The pigment has been found to practically inhibit corrosion on iron and steel even after long exposures, and ranks favorably with all other pigments yet prepared for the elimination of this decay. In consequence, it is rapidly finding its predicted place among paint pigments not only as a protective coating for wood but as a preservative for iron and steel.

picher Iead Co

JOPLIN, MO.

\section{A NEW FORM OF LABORATORY EXTRACTION APPARATUS}

BY A. E. PERKrNS

Received October 25, 1912

The great variety of extraction apparatus now on the market would seem at first thought to supply a form adapted to any purpose; yet, in selecting apparatus for continuous use in a laboratory where large numbers of extractions must be made, one is impressed with the fact that all these forms have in common some of the disadvantages enumerated below.

Most forms of extraction apparatus are very complicated, very expensive and very frail. Nearly all forms have two joints of the cork, ground glass or mercury seal type. These are sources of endless breakage trouble and annoyance, besides furnishing an

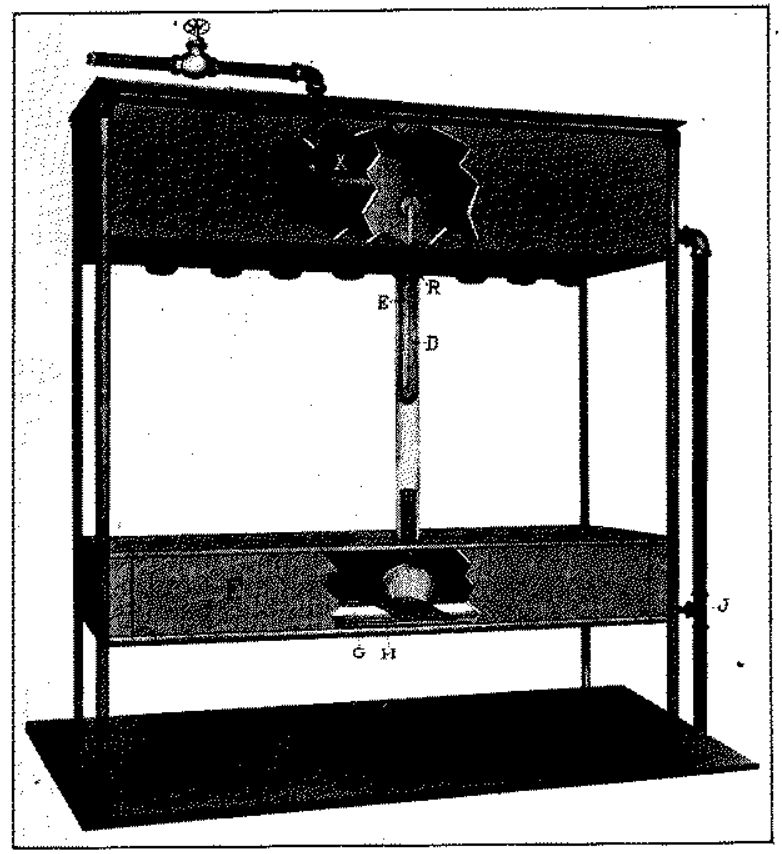

Fing. 1

easy means of contaminating sample or solvent with water leaking from or condensing on the supply pipes. Nearly all the common forms of extraction apparatus must be supplied with water under pressure, which must ordinarily be conveyed to the condenser through rubber tubing. This rubber tubing may frequently break or leak and flood the laboratory, or kink and shut off the water supply; moreover, to keep it in good condition requires continual care and expense.

Efforts by the writer to eliminate certain of these defects from an apparatus to be used in this laboratory

1 Drawings by Mr. Wm. P. Beeching, Jr. have resulted in the construction of the form of apparatus which is here described.

The frame supporting the apparatus (Fig. I) is of $x / 2$ inch metal tubing and has approximate dimensions of $36 \times 32 \times 8$ inches, accommodating 8 extraction flasks which are placed $3^{\pi} / 2$ inches between centers.

The extraction flask A (Fig. 3) is flat bottomed and has a diameter of $2^{3 / 4}$ inches and a height of 2 inches to the base of the neck; the constricted portion of the neck $B$ has height and diameter of about

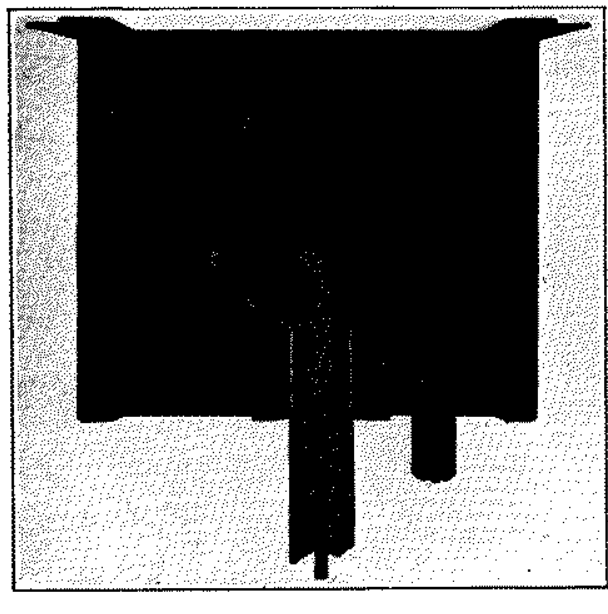

Fira. 2

one-half inch each; the large upper portion of the neck $C^{5}$ has a diameter of $\mathrm{x}^{1} / \mathrm{s}$ inches and a height of $\mathrm{I} 2$ inches. The condenser $\mathrm{D}$ is merely a test tube of special shape ( 9 inches $\times 7 / 8$ inch). The small glass tube $E$ has a diameter of about $3 / 16$ inch. All glass parts are of rather heavy German glass. The dimensions will accommodate any extraction tube up to 5 inches in length and one inch in diameter. A perforated porcelain, or aluminum plate is used to support tubes of small size.

The box F (Fig. I), enclosing the lower part of the extraction flask, is of sheet metal about 4 inches high, the front, back and top being hinged so that they can. be dropped out of the way, leaving the bottom of the box as an open platform when the flasks are being adjusted. The bottom of this box has an opening, $G$, three inches wide and extending the entire length of the box, except for two inches at either end. Heat is supplied by steam passing throutgh a $\mathrm{r} / 4$ inch lead pipe, $H$, which makes three circuits of the box, being separated from the bottom by a layer of asbestos board. The valve controlling the flow of steam is not shown in the drawing. The $1 / 4$ inch lead pipe carrying the exhaust steam enters the waste pipe through a Tee joint, $J$, and extends downward 4 or 5 feet, completely condensing the exhaust steam.

The extraction flask when in position is supported directly over the opening $\mathrm{G}$ by a strip of heavy sheet copper $3 \times 7$ inches in dimensions, the ends of which rest on the steam heating coil, the copper strip serving also to conduct heat to the flask. When the flask is being put into or taken out of position, the copper 
strip is withdrawn and the flask lowered through the opening $G$ until clear of the condenser $D$.

The supply $\operatorname{tank} \mathrm{L}$ (Fig. $x$ ) for the test tube condensers consists of two sheet metal tanks placed one inside the other, $M$ (Fig. 2), and separated by an air space. The bottoms of both tanks are provided with collared holes placed $3^{1} / 2$ inches between centers, the collars for the inside tank $N$ (Fig. 2) being $I^{5} / 2$ inches in diameter and extending downward, those for the outside tank being one inclk in diameter and extending upward into the tank thus overlapping as shown.

The test tube condensers are fitted into the collars of the inner tank with rubber stoppers, $P$ (Fig. 2), being wound with fat free paper or cotton to make a close joint with the outer tank $O$ and with the top of the extraction flask R (Fig. I). The inner tank has a rim $3 / 4$ inch wide extending entirely around it; this rests on the top of the outer tank and thus en-

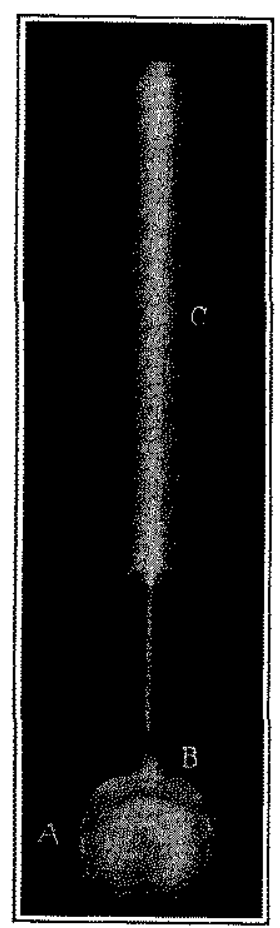

Fus. 3 closes the air space between the two. The inner tank is provided with a partition, $V$, running lengthwise about two inches from the back wall of the tank, the top of the partition being an inch lower than the top of the tank. Collared holes are provided in the partition $S$ (Fig. 2) two inches above and directly opposite the holes in the bottom of the tank; into these are fitted by rubber stoppers, $\mathrm{S}$ and $\mathrm{T}$ (Fig. 2 ), small glass tubes bent downward and extending nearly to the bottom of the test tube condensers as shown in Fig. I. Water from the supply pipe enters the inner tank back of the partition and when its level has risen above the ends of the glass tubes, flows through them into the test tube condensers which overflow into the front chamber of the inner tank. Any excess of water will flow over the partition.

The water supply pipe is narrowed to a $\mathrm{I} / \mathrm{A}$ inch opening and provided with a hood as shown in Fig. $x$; and the waste pipe $U$ which is jointed to the inner tank by means of a rubber stopper is $3 / 4$ inch in diameter, thus eliminating the danger of flooding. By closing the waste pipe and allowing the water to stand 3 or 4 inches deep in the tank practically complete condensation of ether is secured for an indefinite period without running water when the room temperature is not unusually high.

Rapid and complete extractions are secured with this apparatus. Fat determinations are most conveniently made by difference, though the flask has no re-entrant surfaces to prevent complete transfer of the extract to another container for direct weighing.

Most of the faults enumerated above have been avoided in this apparatus. Joints of all kinds have been eliminated from the extraction apparatus proper.
No pipes for distributing water to the condensers and no troublesome rubber tubing connections are needed. Contamination of sample or solvent by water has been made nearly impossible. The glassware costs less than one-fourth as much as most other forms of extraction glassware, and being simpler and stronger it is less liable to breakage.

LABORATORX OF DEPARTMENT OF DAIRYING
OHIO AGRICULTURAL EXPERMMENT STATYON WOOSTER

\section{A DEVICE FOR CONTROLLING SMALL ELECTRIC FURNACES ${ }^{1}$} By Charlies Burton THWang

The plan described herewith for maintaining any desired temperature in a small electric furnace was devised for use with a ro kilowatt carbon plate resistance furnace, for which direct current only was available.

It is usual to employ alternating current for such furnaces, reducing the voltage as the resistance of the furnace falls with the rising temperature.

Where direct current is used, the control is usually effected by means of a rheostat, which, of course, wastes a considerable portion of the energy. The present plan dispenses with the use of a rheostat, by automatically opening the circuit once a minute and closing it after an interval regulated at will.

The control is effected by means of a small motor, which drives, by small gears, a cylindrical cam, C, $250 \mathrm{~mm}$. $\left(9.87^{\prime \prime}\right)$ long and $50 \mathrm{~mm}$. (1.97") in diameter, the cylinder being cut away on a taper from $350^{\circ}$ at $\mathrm{O} / \mathrm{H}$ one end to $0^{\circ}$ at the Electric Furnace Conrror. other. The pawl $P$ is carried on a screw, $s$, which can be turned by the handle $H$ to set the pawl quickly and accurately to any desired position. When the pawl is resting upon the cam, the control switch $\mathrm{S}$ is closed. This automatically closes the clapper switch carrying the current; when the paw1 drops, the control switch $S^{\prime}$ is closed, opening the clapper switch and cutting off the supply of energy from the furnace.

It is evident that the fractional amount of time during which the current is supplied to the furnace varies with the position of the pawl on the cam. While heating the furnace, the automatic switch is at rest; when the desired temperature has been attained, the motor which actuates the switch is started and the cam set to the position which has been found by trial to furnish the energy required to balance the losses by radiation. The pawl may be set with ease to within I mm. $\left(0.03937^{\prime \prime}\right)$, which is, of course, a finer adjustment than is required.

The control of the furnace is further effected by placing in series with the carbon resistance an auxiliary resistance of $0.2 \mathrm{ohm}$ of nichrome tape, which in-

1 Paper presented at the Eighth International Congress of Applied Chemistry, New York, September, 1912. 